\title{
Impact of model reduction on the dynamic simulation of a micro-scale concentrated solar power system integrated with a thermal storage
}

\author{
Rémi Dickes*, Noé Weber, Vincent Lemort and Sylvain Quoilin \\ Energy Systems Research Unit \\ Aerospace and Mechanical Engineering Department, Faculty of Applied Sciences \\ University of Liège (Belgium) \\ *corresponding author: rdickes@ulg.ac.be
}

\begin{abstract}
Because of the intermittent nature of solar irradiances, micro-scale solar thermal power systems almost never operate in nominal operating conditions. They are characterized by strong transients and require robust, fast and accurate dynamic simulation tools to permit a proper evaluation of their performance. Model reduction, i.e. the simplification of detailed models, is an attractive method to improve the computational efficiency while simulating such systems. In this context, a $\mu$ CSP plant featuring a solar field of parabolic troughs, a thermocline storage and a $5 \mathrm{kWe}$ power unit is investigated. Both the solar field and the thermocline storage are modeled with complex and simplified methods. The whole power plant is simulated under identical operating condition and deviations between the simulation results are analyzed. Benefits and limitations of the current modeling approach are assessed. Improvements for the modeling of the thermocline storage are identified, implemented and validated. The Modelica language is used as simulation tool and the models developed in this work are integrated in the open-source ThermoCycle library.
\end{abstract}

Keywords: thermocline storage, concentrated solar power, model reduction, dynamic modeling

\section{Introduction}

Energy security issues and global warming due to the extensive use of fossil fuels are nowadays almost universally recognized (IEA, 2015). Together with other growing technologies, concentrated solar power (CSP) is increasingly developed to help extend the share of renewable energy in the world's power generation (IEA, 2014). A major advantage of CSP over other technologies is the ability to couple the solar thermal power plant with a simple and cost-effective thermal energy storage (TES). Surplus of thermal power collected by the solar field during sunny periods can be easily stored to be latter used in low radiation conditions, hence improving the plant's capacity factor, its flexibility and reducing the cost of electricity. Besides well-known large-scale applications (Lovegrove and Stein, 2012), concentrated solar power can also be used in micro-systems ( $\mu$ CSP) for supplying useful heat and electricity to a local demand, e.g. in remote off-grid areas (Orosz, 2012). Given the intermittent nature of solar irradiances and the local energy demand, $\mu$ CSP systems often work far from their nominal design conditions and are submitted to strong transients. Powerful dynamic modeling tools are therefore required to simulate the effective performance of $\mu$ CSP systems in real operating conditions and to optimize the control strategy. However, high computational speed, robustness and accuracy must be achieved by the dynamic models to permit a direct application of these tools in optimization problems. An interesting method to reach such goals is to use simplified models for simulating each component of the power plant. This method is referred to as model reduction and is the subject of this contribution. 


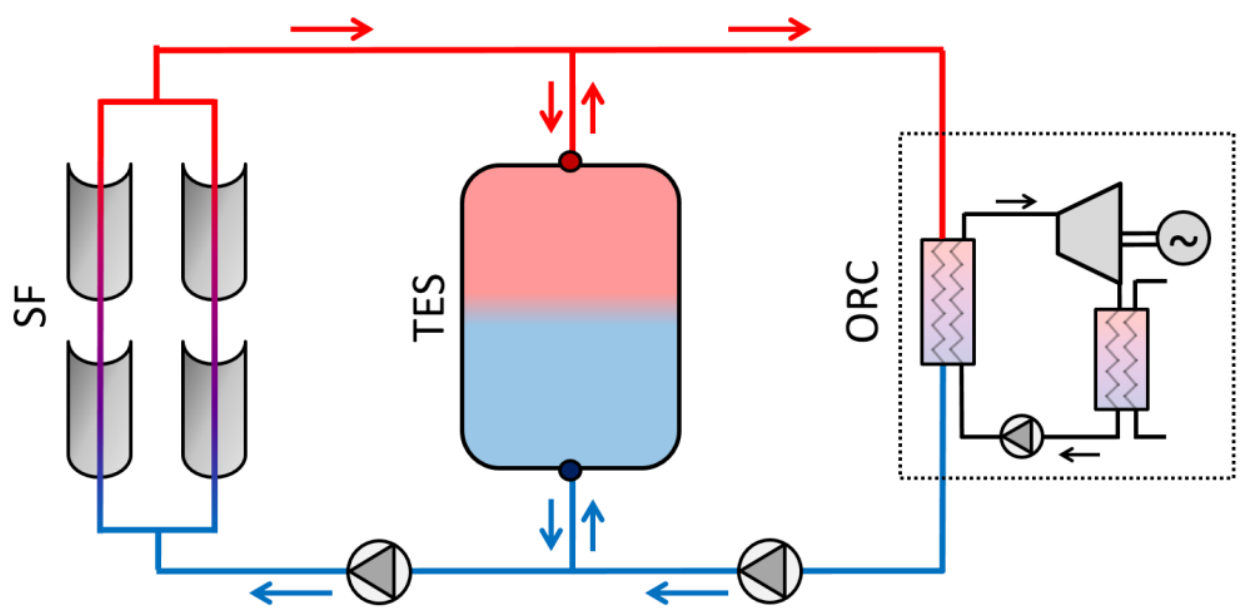

Fig. 1: Schematic layout of the $\mu$ CSP plant considered in this work (red lines: hot HTF - blue line: cold HTF).

The CSP system considered here is depicted in Figure 1. The power plant features a solar field (SF) of parabolic trough collectors $\left(130 \mathrm{~m}^{2}\right)$, a $5 \mathrm{kWe}$ non-recuperative organic Rankine cycle (ORC) and a thermocline storage $\left(15 \mathrm{~m}^{3}\right)$. Therminol 66 is used as heat transfer fluid (HTF) and two circulating pumps control its flow rate through the solar field, the TES and the ORC. For the sack of conciseness, neither the control strategy nor technical data of the power plant are described in this manuscript. Detailed information regarding these aspects is available in a previous article also dedicated to this research project (Dickes et al., 2014).

In a previous work (Dickes et al., 2015a), the authors proposed two innovative approaches for modeling both the solar field and the thermocline storage. These methods aimed to simplify the simulation of these components by making the models less complex. In order to assess the loss of accuracy caused by the simplified approaches, results of simulation in identical operating conditions were compared with predictions given by deterministic (i.e. detailed) models. However, this comparison was only performed for each component individually. In this contribution, it is proposed to further evaluate the validity of model reduction by simulating the whole $\mu$ CSP plant with both detailed and simplified methods. Only the solar collectors and the thermal energy storage are studied in details. Model reduction of the organic Rankine cycle is beyond the scope of this report. Results of simulation under identical operating conditions are compared and analyzed to assess the limits and benefits of the current approach. Improvements required for the modeling of the thermal storage are identified, developed and validated.

The Modelica language (Elmqvist and Mattsson, 1997) is used as simulation platform and thermo-physical properties of the fluids are computed with the free-access CoolProp library (Bell et al., 2014). Furthermore, all the models developed in the frame of this project are included in the open-source ThermoCycle library (Quoilin et al., 2013) dedicated to the modeling of thermal systems and under development at the University of Liège. Results presented in this paper are mostly derived from a MSc thesis performed by Noé Weber at the University of Liège. Additional information unpublished in this paper can be found in the original manuscript (Weber, 2015).

\section{Model reduction and global simulation}

In this section, a short description of the models already developed for the thermal storage and the solar field is first given. Additional information about the models development and the results of the individual comparison can be found in the authors' preceding publication (Dickes et al., 2015a). The whole power plant is then simulated by coupling together the solar field and the thermocline storage. Results from detailed and simplified models in identical weather conditions are then discussed and analyzed. For the sake of clarity, the different models developed in the following sections, with their main characteristics, are summarized in the Appendix (see Table 2). 


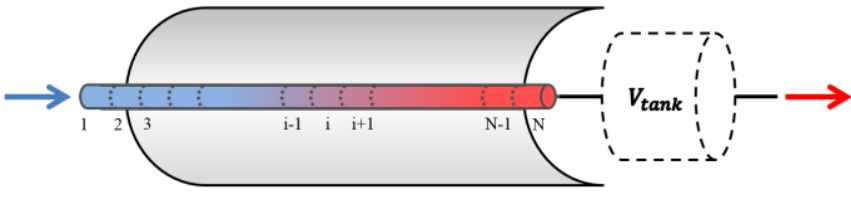

Fig. 2: one-dimensional discretization of a PTC (with a fictive tank connected to the outlet for the simplified model)

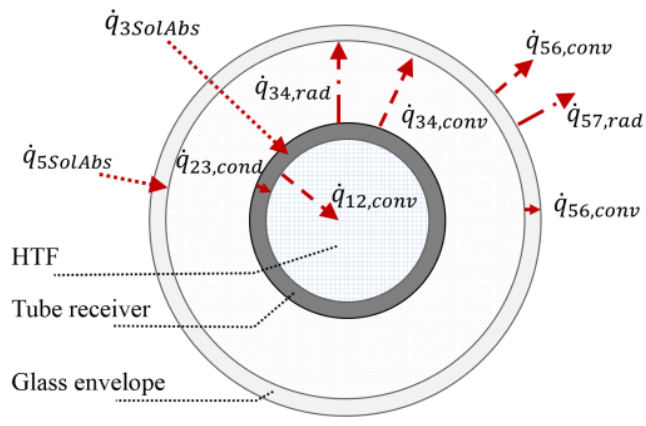

Fig. 3: Radial heat balance taking place in a parabolic trough collector

\subsection{Solar thermal collectors - description of the simplified and the detailed models}

Parabolic trough collectors (PTCs) are linear concentrating systems made of long, parabolic-shaped mirrors and an absorber tube placed along the focal axis of the parabola. In order to evaluate the temperature profile of the heat transfer fluid circulating along the receiver tube, a common approach is to discretize the tube along its axial axis in a number of cells of constant volume in which the energy balance is evaluated (see Figure 2). In order to determine the net heat power absorbed by the fluid in each cell, two options are proposed as described here below.

- $\quad$ Detailed method (referred to as model PTC $C_{A}$ ): as depicted in Figure 3, the net heat power absorbed by the HTF can be evaluated by solving the radial heat balance between the surrounding environment, the glass envelop, the absorber tube and the fluid (Forristall, 2003). To account for the dynamic behavior of the collectors in transient operating conditions, thermal capacitances of the different components are considered. The number of cells used for the discretization is a key parameters that must be selected correctly. It must be high enough to limit the effects of numerical diffusion (Peterson, 1992) while ensuring low computational times.

- $\quad$ Simplified method (referred to as model $P T C_{\underline{B}}$ ): an alternative approach to calculate the net heat power absorbed by the HTF is to use a calibrated correlation computing the effective heat losses of the PTC in function of the operating conditions (Dickes et al., 2015b). By using such correlation, the steady-state temperature profile along the collectors can be easily derived. The dynamic response of the parabolic troughs is accounted by connecting a fictitious fluid reservoir in series with the solar field outlet, as shown in Figure 2. The reservoir acts as a dynamic damper and smooth out the temperature changes simulated by steady-state model at the solar field outlet.

Results from the individual comparison demonstrate good agreements between the two modeling methods in most working conditions. Significant deviations are observed for fast transient conditions (i.e. with time constants lower than the residence time of the fluid within the collectors). Indeed, the single reservoir used as thermal inertia does not properly simulate the progression of the temperature gradients within the collector tubes. However, these fast effects are localized and remain negligible in long-term simulations.

\subsection{Thermocline storage - description of the simplified and detailed models}

The storage system used in the $\mu$ CSP plant is a single-tank stratified storage, also called thermocline storage. It is entirely filled with heat transfer fluid and, by taking advantage of the vertical stratification due to the density gradient, both cold and hot zones are stored in a single reservoir. Like for the solar collectors, two modeling methods are used to characterize the thermocline storage. 


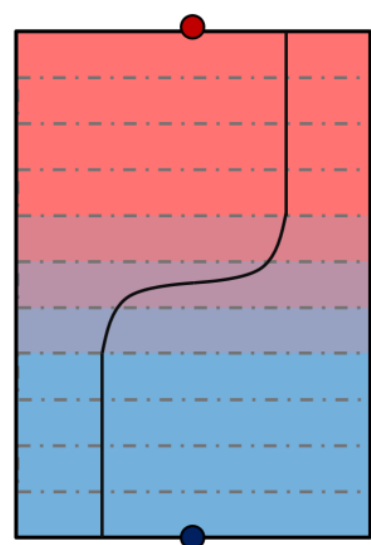

Fig. 4: one-dimensional finite-volume method for modeling a thermocline storage

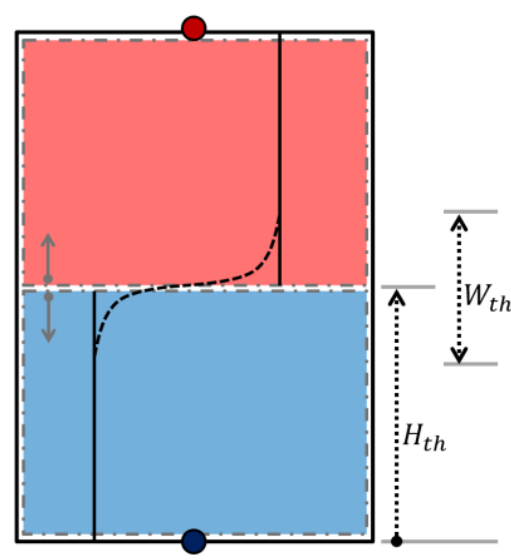

Fig. 5: two-zone moving-boundary method for modeling a thermocline storage

- Detailed method (referred to as model $T E S_{A}$ ): in a physically-based approach, a thermocline system can be modeled with a one-dimensional finite-volume method. The reservoir is assumed cylindrical and discretized along its vertical axis in a finite number of isothermal cells of constant volume (as illustrated in Figure 4). In each cell, both mass and energy balances are evaluated while accounting for heat losses to the environment, mass exchange and conductive heat transfer between adjacent cells. Because of the low velocity of the fluid within the tank, a high discretization must be performed to limit the effect of numerical diffusion, resulting in long computational time. In this paper, a 200-cell discretization is chosen for the detailed model $\mathrm{TES}_{\mathrm{A}}$.

- Simplified method (referred to as model $T E S_{B}$ ): a simpler approach to simulate a thermocline storage is to consider a two-zone moving-boundary model. The tank is divided into two isothermal zones, a hot and a cold one, of variable volume. Mass and energy balance only need to be calculated twice, once for each zone, which drastically increases simulation speed. If the tank is fully charged (resp. discharged), then only the hotter zone (resp. the colder zone) subsists in the tank. The temperature transition profile between the two zones is modelled as half a period of a cosine symmetrically centered on the boundary between the two zones, as depicted in Figure 5. In a first time, the thickness of the thermocline region ( $\mathrm{W}_{\text {th }}$ in Figure 5) is assumed constant, whatever the operating conditions.

Results from the individual comparison demonstrate good agreements between the two modeling methods if a proper calibration of the thermocline thickness is performed. Furthermore, the simplified method demonstrate a drastic decrease in the simulation time (up to 99\%) when compared to the deterministic model.

\subsection{Power plant simulation}

In order to further evaluate the validity of the simplified models, the whole power plant is simulated during

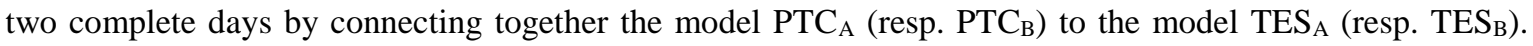
The same control strategy is applied for the circulating pumps and identical weather conditions are used as inputs. The first day has a quasi-perfect solar irradiance shape and it is used as reference to calibrate the thermocline thickness $\mathrm{W}_{\text {th }}$ of the simplified model $\mathrm{TES}_{\mathrm{B}}$. As depicted in Figures 6 and 7 , really good agreements are found between the simplified and the detailed simulations. Regarding to the solar field, both the outlet temperature and the mass flow rate are reproduced with high precision during shinny periods. It can also be seen that deviations in the outlet temperature prediction arise only in strong off-design conditions. However, these periods correspond to zero-flow conditions in the solar field which do not influence the rest of the power plant. The thermal storage is also well represented with the simplified model $\mathrm{TES}_{\mathrm{B}}$. As depicted in Figure 7, both the thermocline position $\left(\mathrm{H}_{\mathrm{th}}\right.$ in Figure 5$)$ and the discharge temperature at the top port of the storage are correctly simulated along the day. Although promising, these results are biased since the thermocline thickness $\mathrm{W}_{\text {th }}$ of the model $\mathrm{TES}_{\mathrm{B}}$ has been calibrated a posteriori to fit properly the predictions of the complex model. 
Dickes et al. / SWC 2015 / ISES Conference Proceedings (2015)
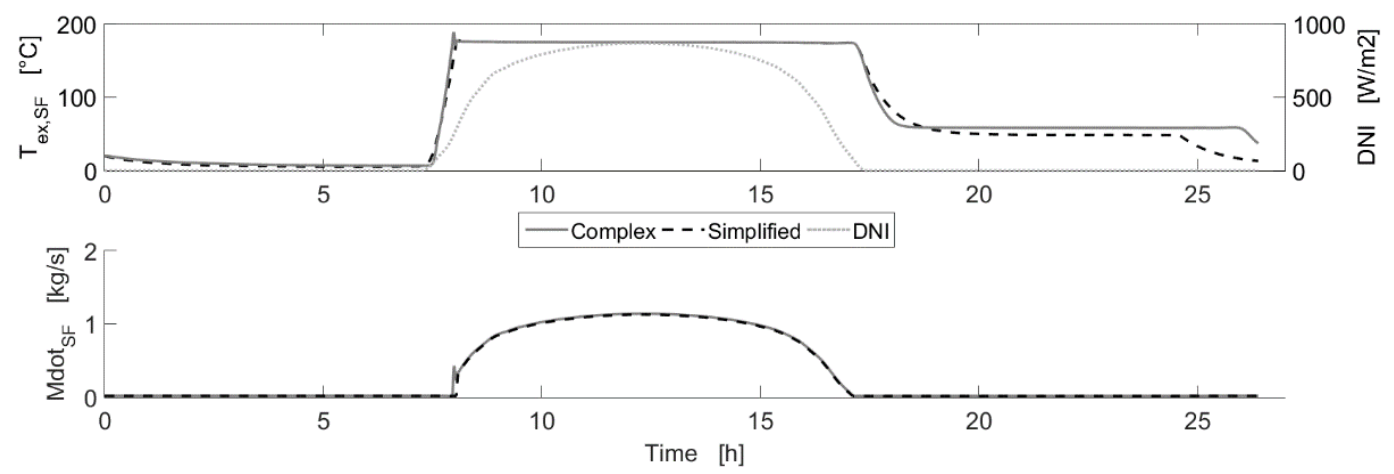

Fig. 6: Day 1 - Outlet temperature (top fig.) and mass flow rate (bottom fig.) modeled in the solar field
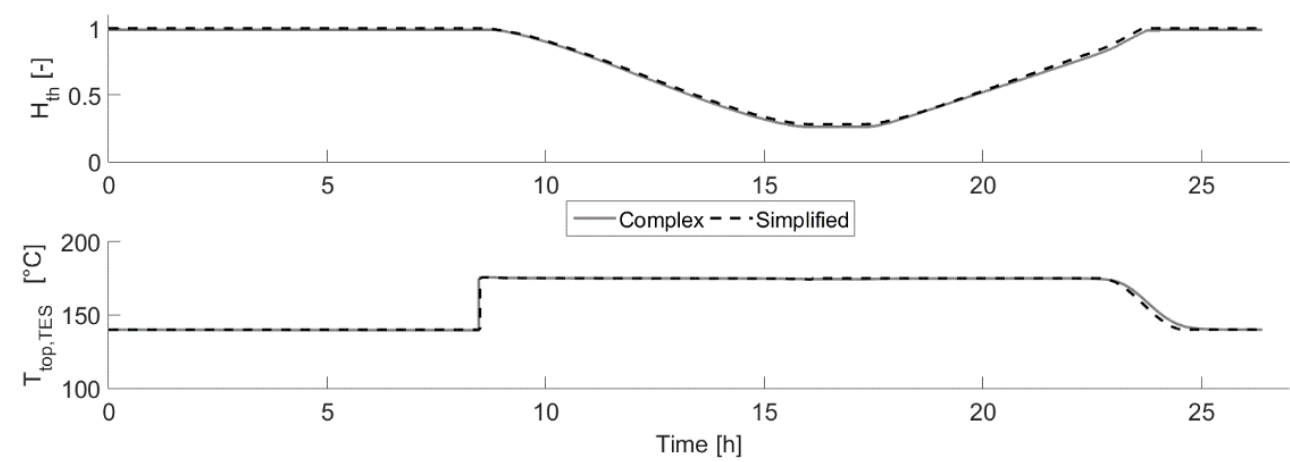

Fig. 7: Day 1 - Thermocline position in the tank (top fig.) and discharge temperature at the top port of the TES (bottom fig.)
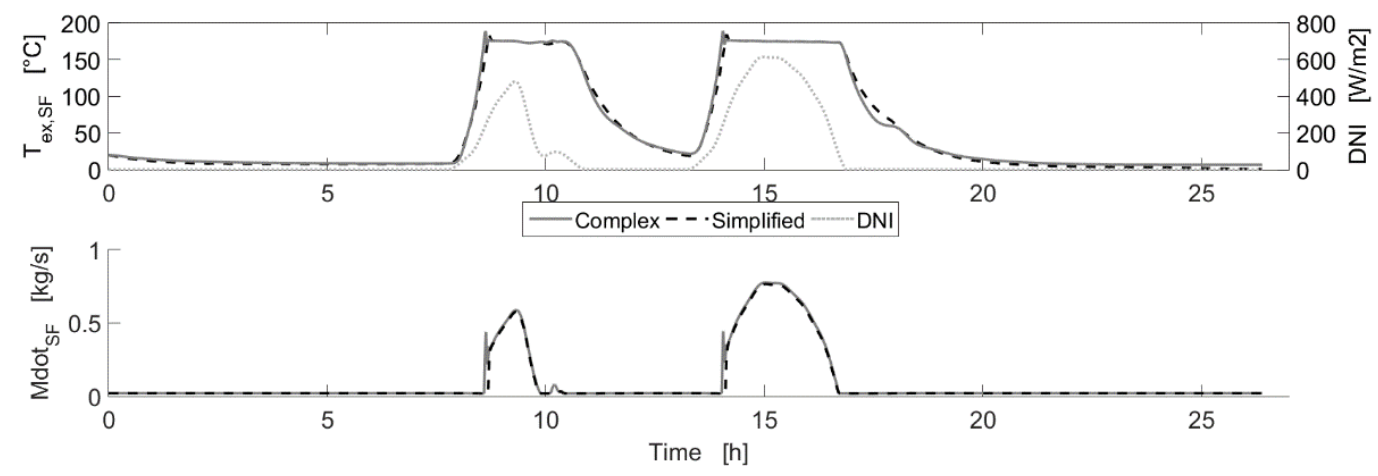

Fig. 8: Day 2 - Outlet temperature (top fig.) and mass flow rate (bottom fig.) modeled in the solar field
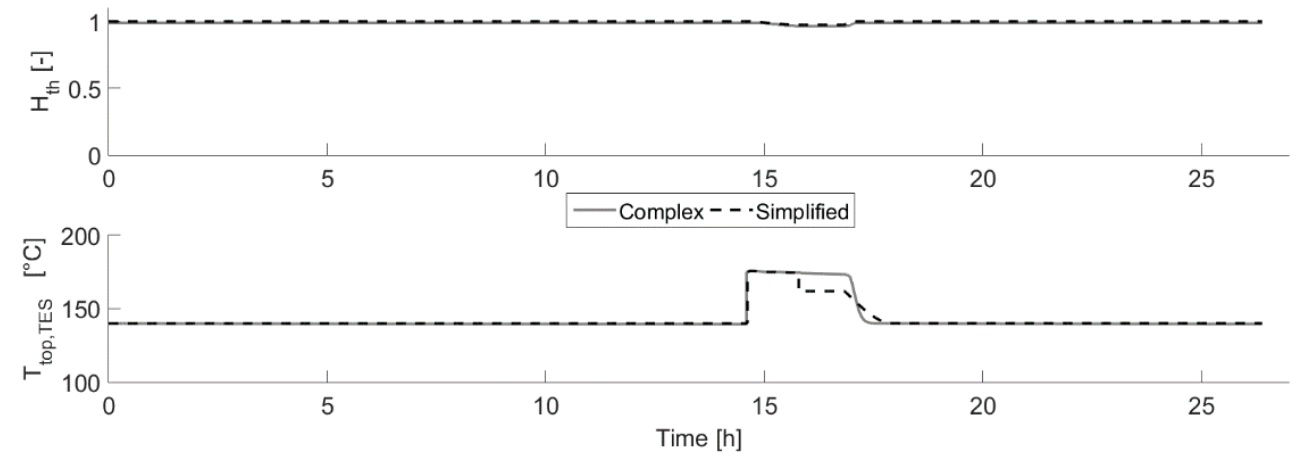

Fig. 9: Day 2 - Thermocline position in the tank (top fig.) and discharge temperature at the top port of the TES (bottom fig.) 
The power plant is simulated during a second day characterized by poorer solar conditions and the thermocline thickness is kept unchanged. As shown in Figure 8, parabolic troughs are once again simulated correctly and good agreements are observed for both the mass flow and the outlet temperature of the solar field. Concerning the thermal energy storage, results are less enthusiastic. The assumption of a constant thermocline thickness leads to significant mispredictions of the discharge temperature at the top port of the tank, as illustrated in Figure 9. Indeed, the simplified model considers the thermocline as a fixed transition profile moving together with two sub-volumes. If a flow reversal happens before the storage is charged enough to have the "hypothetical" thermocline zone entirely comprised inside the tank, a nonphysical discontinuity of the temperature is simulated at the top port of the storage. Same errors also occur in the case of partial discharge of the TES. For more information about this numerical problem, a detailed description of the phenomena is provided in Weber's thesis (Weber, 2015). This observation poses the problem that, with the present simplified method, the thermocline thickness must be fitted a posteriori, when the results of the complex model are already available. A convenient method to thwart the issue is to determine the dynamic evolution of the thermocline thickness in the storage throughout the day, as a function of real-time parameters, so that the model could be used with no need of retrofitting. The next section is devoted to the development of such model.

\section{Model improvements of the thermocline storage and global simulation}

It this section, the methodology used to develop an improved model of the thermal energy storage is presented. This new model is then validated by simulating the complete power plant over the same two days as in section 2.3.

\subsection{Thermocline storage - modelling improvement}

As explained previously, the thermocline thickness within a stratified tank does not remain constant and making such an assumption leads to significant mispredicitons. In order to derive a law that represents the dynamic evolution of the thermocline thickness, the dynamics taking place inside the tank are simulated with the detailed model $\mathrm{TES}_{\mathrm{A}}$ in various conditions. Evolutions of the thermocline thickness with different mass flow rates in both charging and discharging modes, but also in standby conditions, are calculated and analyzed. Results demonstrate that the evolution of the thermocline thickness is mainly function of the time and the fluid mass flow rate. As depicted in Figure 10 (in the case of charging processes), the thermocline thickness $W_{\text {th }}$ can be interpolated by an equation of the form

$$
W_{t h}=K_{t h} \cdot \sqrt{t}
$$

where $t$ is the time since the beginning of the charge and $K_{t h}$ is a parameter depending of the mass flow rate $\dot{m}$, i.e.

$$
K_{t h}=a \cdot \sqrt{\dot{m}}+b
$$

as illustrated in Figure 11. Coefficients $a$ and $b$ in equation 2 are calibrated for both charging and discharging processes and their values are provided in the Appendix. Regarding standby periods, it is found that the thermocline thickness increases linearly with respect to the time i.e.

$$
W_{t h}=c_{s b} \cdot t
$$

where $c_{s b}$ is another constant parameter given in the Appendix. By implementing these correlations in the two-zone moving-boundary model, an improved approach for simulating the thermocline storage (referred to as model $T E S_{C}$ ) is finally obtained. 


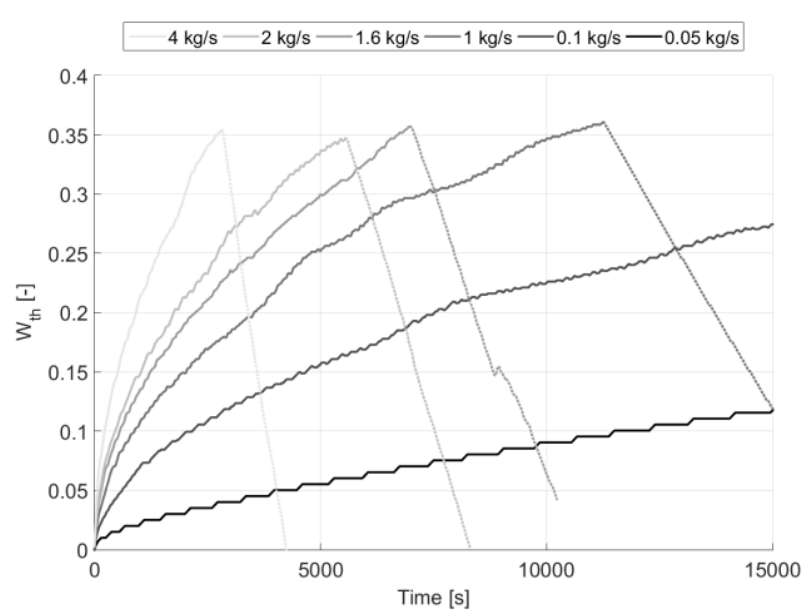

Fig. 10: Evolution of the thermocline thickness as a function of time with various mass flow rates

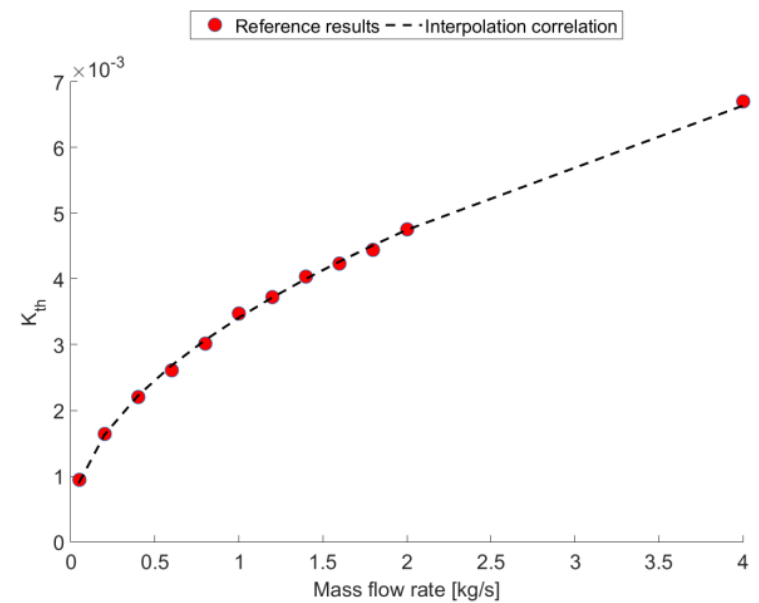

Fig. 11: Evolution of the parameter $K_{t h}$ as a function of the mass flow rate

\subsection{Power plant simulation}

In order to validate the new model $T E S_{C}$ presented here above, the whole power plant is simulated during the same two days as in section 2.3, and results obtained by the combination of models $\mathrm{PTC}_{\mathrm{B}}-\mathrm{TES}_{\mathrm{C}}$ are compared to the reference/detailed model $\mathrm{PTC}_{\mathrm{A}}-\mathrm{TES}_{\mathrm{A}}$. Since the simplified method for modeling of solar field has demonstrated to be reliable, only results relative to the thermal storage are depicted in Figure 12 and 13; these figures corresponding to the first and the second day respectively. It can be seen that, for both days, the two-zone moving-boundary approach permits once again to predict correctly the position of the thermocline inside the tank (i.e. $H_{t h}$ in Figure 5). Furthermore, the correlations used to compute dynamically the thermocline thickness permit to replicate much better the behavior of the storage. Without any precalibration, the evaluation of the thickness $W_{t h}$ is properly predicted for both days and mispredictions of the discharge temperature are drastically decreased compared to results of the initial model $\mathrm{TES}_{\mathrm{B}}$. Simulations performed for two other days can be found in Weber's thesis (Weber, 2015) and identical observations are drawn. In conclusion, the new model TES $\mathrm{C}_{\mathrm{C}}$ of the thermocline coupled to the simplified model $\mathrm{PTC}_{\mathrm{B}}$ of the solar collectors permit to replicate correctly predictions of the complex models.
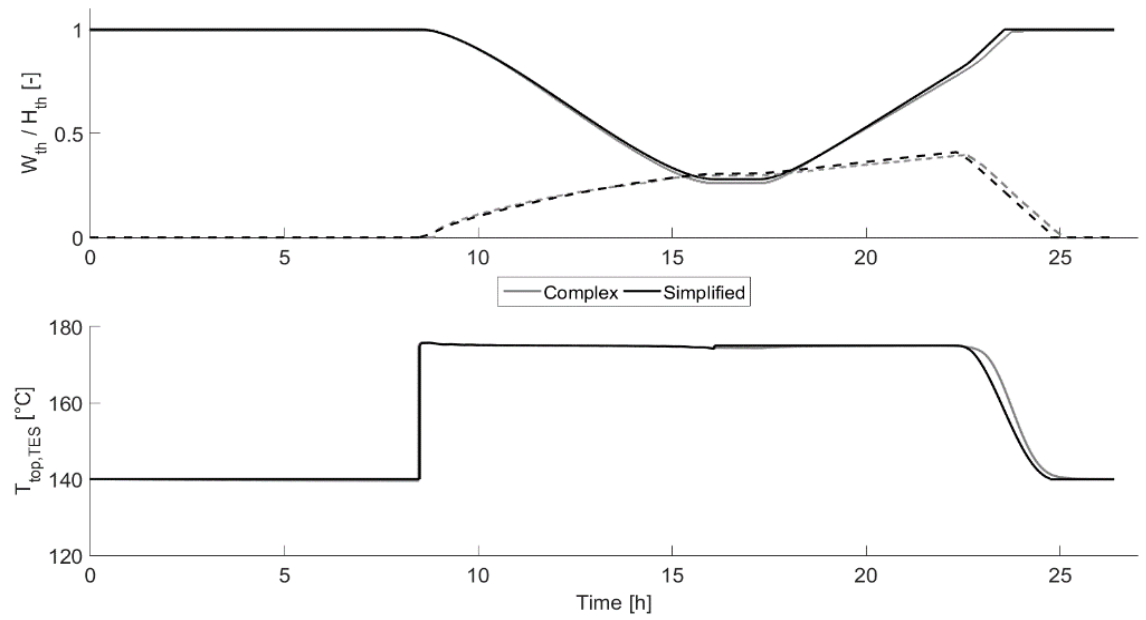

Fig. 12: Day 1 -Position $H_{\text {th }}$ and thickness $W_{\text {th }}$ of the thermocline inside the tank (top) and discharge temperature at the top port of the TES (bottom) 

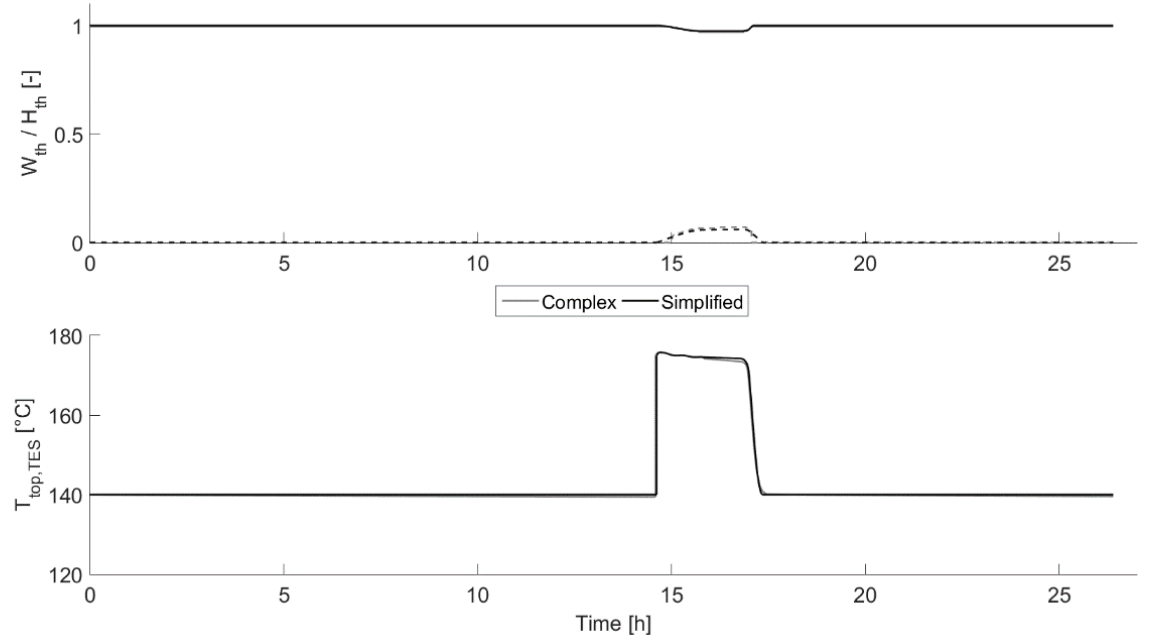

Fig. 13: Day 2 -Position $H_{\text {th }}$ and thickness $W_{\text {th }}$ of the thermocline inside the tank (top) and discharge temperature at the top port of the TES (bottom)

\section{Simulation speed, number of variables and accuracy}

In the previous sections, it is shown that simplified modeling methods can be used instead of complex ones to simulate a small-scale solar thermal power plant. The main motivation of this approach is to improve numerically the simulations by increasing the computational speed. In order to highlight such an improvement, both the number of variables and the simulation times required by the three models investigated in this paper are summarized in Table 1. All the simulations were run on Dymola@ 2015 with an Acer Aspire V5, CPU Intel Core i5 2.7 Ghz, 8GB RAM.

A first observation is the sharp decrease in the number of variables between the two simplified models and the reference case (up to $90 \%$ for the complete power plant). As explained previously, the detailed model of the storage $\left(\mathrm{TES}_{\mathrm{A}}\right)$ needs to solve the energy and the mass balances in the 200 discretized cells, whereas both simplified methods $\left(\mathrm{TES}_{\mathrm{B}}\right.$ and $\mathrm{TES}_{\mathrm{C}}$ ) only consider two sub-tanks of variable volume. The additional correlations implemented in the model $\mathrm{TES}_{\mathrm{C}}$ increase slightly the number of variables but these remains largely fewer than for the detailed model $\mathrm{TES}_{\mathrm{A}}$. Regarding the solar field, the deterministic calculation of the radial heat balance in each cell requires almost 3000 variables whereas the simplified method reduces this number to 600. Besides the number of variables, it can be seen that simplified models are between 75 and 215 times faster than the detailed one. The tremendous gain in computational speed is extremely valuable when performing long-term simulations, or when using directly these dynamic modeling tools in iterative problems like optimizations.

Tab. 1 - Number of variables and simulation times for each model of the complete power plant (with the relative reduction compared to the reference case given in parenthesis)

\begin{tabular}{llllll}
\cline { 2 - 6 } & $\begin{array}{l}\text { Detailed model } \\
\left(\mathbf{P T C}_{\mathbf{A}}-\mathbf{T E S}_{\mathbf{A}}\right)\end{array}$ & \multicolumn{2}{l}{$\begin{array}{l}\text { Simplified model } \\
\left(\mathbf{P T C}_{\mathbf{B}}-\mathbf{T E S}_{\mathbf{B}}\right)\end{array}$} & \multicolumn{2}{l}{$\begin{array}{l}\text { Improved model } \\
\left(\mathbf{P T C}_{\mathbf{B}}-\mathbf{T E S}_{\mathbf{C}}\right)\end{array}$} \\
\hline No. of variables (TES) & 4607 & 77 & $(-98 \%)$ & 442 & $(-90 \%)$ \\
No. of variables ( $\boldsymbol{\mu C S P})$ & 7602 & 735 & $(-90 \%)$ & 1100 & $(-85 \%)$ \\
Simulation time (Day 1) & $5680 \mathrm{sec}$ & $75 \mathrm{sec}$ & $(-98 \%)$ & $66 \mathrm{sec}$ & $(-99 \%)$ \\
Simulation time (Day 2) & $9960 \mathrm{sec}$ & $46 \mathrm{sec}$ & $(-99 \%)$ & $43 \mathrm{sec}$ & $(-99 \%)$ \\
\hline
\end{tabular}




\section{Conclusion and future work}

Because of the intermittent nature of solar irradiances, $\mu$ CSP systems almost never operate in nominal working conditions. They are characterized by strong transients and require powerful dynamic simulation tools to permit a proper evaluation of their performance. Model reduction, i.e. the simplification of detailed model, is an attractive method to improve the computational efficiency when simulating such systems. In this context, a $\mu$ CSP plant consisting of a thermocline storage, a solar field of parabolic trough collectors and a $5 \mathrm{kWe}$ ORC is considered. Both complex and simplified models are developed for the solar field and the thermal energy storage.

In a previous work, an individual comparison applied to each component demonstrated the great potential of simplified methods to replicate predictions of the detailed models. In this contribution, it is proposed to further evaluate the validity of model reduction by simulating the whole $\mu$ CSP plant under identical operating conditions by connecting together these detailed and simplified models. Results demonstrate good agreements for the solar collectors. However, the initial assumption of a constant thermocline thickness in the thermal storage leads to significant errors. Therefore, empirical correlations are identified and implemented in the model to simulate the dynamic evolution of the thermocline thickness within the tank as a function of real-time parameters. This new model of the storage is integrated in the $\mu$ CSP plant and much better results are demonstrated. Regarding numerical aspects, the number of variables is drastically decreased by using the simplified models, e.g. $85 \%$ less when considering the complete power plant. Besides increasing the robustness, the reduced number of variables permits the simplified models to achieve much faster computational speed for a same simulation (up to $99 \%$ less time).

In conclusion, model reduction has demonstrated to be a convenient and powerful tool to permit a direct application of dynamic modeling in iterative problems (e.g. control optimization) or for long-term simulations. Really good agreements are found between simulation results of the simplified and the detailed models, but there is still room for improvements. As an example, future works include to change the shape of the transition profile implemented in the two-zone moving-boundary model of the TES. Indeed, better accordance with the complex model could be achieved by using a LCDF function (Bayón and Rojas, 2014).

\section{Appendix}

Tab. 1 - Characteristics of the different models investigated for the solar field and the thermal storage

\begin{tabular}{|c|c|c|c|c|}
\hline \multicolumn{2}{|c|}{ Solar field } & \multicolumn{3}{|c|}{ Thermocline TES } \\
\hline model PTC A $_{A}$ & model PTC & model TES $_{A}$ & model TES & model TESC $_{C}$ \\
\hline Detailed & Simplified & Detailed & Simplified & Simplified bis \\
\hline $\begin{array}{l}\text { (solves the radial } \\
\text { heat balance and } \\
\text { accounts for the } \\
\text { thermal inertia of } \\
\text { the different } \\
\text { component in } \\
\text { balance in each } \\
\text { cell) }\end{array}$ & $\begin{array}{l}\text { (uses a semi- } \\
\text { empirical correlation } \\
\text { to calculate the } \\
\text { steady-state } \\
\text { temperature profile } \\
\text { and a single fictive } \\
\text { reservoir at the solar } \\
\text { field outlet) }\end{array}$ & $\begin{array}{l}\text { (tank discretized } \\
\text { in } 200 \text { cells of } \\
\text { constant volume } \\
\text { and evaluation of } \\
\text { both the mass and } \\
\text { the energy } \\
\text { balance in each } \\
\text { cell) }\end{array}$ & $\begin{array}{l}\text { (two-zone moving- } \\
\text { boundary model of } \\
\text { the storage with a } \\
\text { constant } \\
\text { thermocline } \\
\text { thickness in any } \\
\text { operating } \\
\text { conditions) }\end{array}$ & $\begin{array}{l}\text { (two-zone moving- } \\
\text { boundary model of } \\
\text { the storage with a } \\
\text { dynamic calculation } \\
\text { of the thermocline } \\
\text { thickness in function } \\
\text { of the operating } \\
\text { conditions) }\end{array}$ \\
\hline
\end{tabular}


Dickes et al. / SWC 2015 / ISES Conference Proceedings (2015)

Tab. 3 - Coefficients of the correlations used to calculate the thermocline thickness

\begin{tabular}{ll}
\hline Name & Value \\
\hline$a_{c h}$ & $3.23 e-3$ \\
$b_{c h}$ & $1.86 e-4$ \\
$a_{\text {disch }}$ & $2.97 e-3$ \\
$b_{\text {disch }}$ & $9.98 e-4$ \\
$c_{s b}$ & $6.74 \mathrm{e}-7$ \\
\hline
\end{tabular}

\section{Nomenclature}

\section{Acronyms}

CSP Concentrated Solar Power

DNI Direct Normal Irradiance

HTF Heat Transfer Fluid

ORC Organic Rankine Cycle

PTC Parabolic Trough Collector

SF $\quad$ Solar Field

TES Thermal Energy Storage

\section{Subscripts}

$\begin{array}{ll}\text { A } & \text { model A } \\ \text { B } & \text { model B } \\ \text { C } & \text { model C } \\ \text { ch } & \text { charging } \\ \text { disch } & \text { discharging } \\ \text { ex } & \text { exhaust } \\ \text { sb } & \text { standby } \\ \text { th } & \text { thermocline } \\ \text { top } & \text { top port of the storage }\end{array}$

\section{Symbols}

a Coefficient of interpolation, -

b Coefficient of interpolation, -

c Coefficient of interpolation, -

$\mathrm{H} \quad$ Normalized height, -

K Coefficient of interpolation, -

Mdot, $\dot{m} \quad$ Mass flow rate, $\mathrm{kg} / \mathrm{s}$

$\mathrm{T} \quad$ Temperature, ${ }^{\circ} \mathrm{C}$

$\mathrm{t} \quad$ Time, sec

$\mathrm{V} \quad$ Volume, $\mathrm{m}^{3}$

W Normalized thickness, - 


\section{References}

Bayón, R., Rojas, E., 2014. Analytical function describing the behaviour of a thermocline storage tank: A requirement for annual simulations of solar thermal power plants. Int. J. Heat Mass Transf. 68, 641648.

Bell, I.H., Wronski, J., Quoilin, S., Lemort, V., 2014. Pure and pseudo-pure fluid thermophysical property evaluation and the open-source thermophysical property library coolprop. Ind. Eng. Chem. Res. 53, 2498-2508.

Dickes, R., Desideri, A., Bell, I., Quoilin, S., Lemort, V., 2014. Dynamic modeling and control strategy analysis of a micro-scale CSP plant coupled with a thermocline system for power generation, in: Proceedings of Eurosun ISES 2014. Aix-les-Bains (France).

Dickes, R., Desideri, A., Lemort, V., Quoilin, S., 2015a. Model reduction for simulating the dynamic behavior of parabolic troughs and a thermocline energy storage in a micro-solar power unit, in: Proceedings of ECOS 2015. Pau (France).

Dickes, R., Lemort, V., Quoilin, S., 2015b. Semi-empirical correlation to model heat losses along solar parabolic trough collectors, in: Proceedings of ECOS 2015. Pau (France).

Elmqvist, H., Mattsson, S.E., 1997. Modelica - the Next Generation Modeling Language an International Design Effort, in: Proceedings of the 1st World Congress on System Simulation. Singapore.

Forristall, R., 2003. Heat Transfer Analysis and Modeling of a Parabolic Trough Solar Receiver Implemented in Engineering Equation Solver, Contract. Golden, CO.

IEA, 2015. International Energy Agency - Report on Energy Security [WWW Document]. URL http://www.iea.org/topics/energysecurity/

IEA, 2014. International Energy Agency -Technology Roadmap: Solar Thermal Electricity [WWW Document]. URL http://www.iea.org/

Lovegrove, K., Stein, W., 2012. Concentrating solar power technology - Principle, developments and application, Woodhead Publishing Series in Energy. Woodhead Publishing.

Orosz, M.S., 2012. Thermosolar and photovoltaic hybridization for small scale distributed generation: application for powpower rural health. Massachusetts Institue of Technology.

Peterson, P.F., 1992. A method for predicting and minimizing numerical diffusion. Numer. Heat Transf. Part B Fundam. An Int. J. Comput. Methodol. 21, 343-366.

Quoilin, S., Desideri, A., Bell, I., Wronski, J., Lemort, V., 2013. Robust and computionally efficient dynamic simulation of ORC systems: the Thermocycle modelica library, in: Proceedings of the AMSE-ORC Conference 2013. Rotterdam (NL).

Weber, N., 2015. Dynamic model reduction of a thermocline storage integrated in a micro-scale solar power plant. University of Liège. 